\title{
Repression of Activated Aryl Hydrocarbon Receptor-Induced Transcriptional Activation by $5 \alpha$-Dihydrotestosterone in Human Prostate Cancer LNCaP and Human Breast Cancer T47D Cells
}

\author{
Noriko Sanada $^{1}$, Yuka Gotoh ${ }^{1}$, Rumiko Shimazawa, ${ }^{1, \#}$, Carolyn M. Klinge ${ }^{2}$, and Ryoichi Kizu ${ }^{1, *}$ \\ ${ }^{1}$ Faculty of Pharmaceutical Sciences, Doshisha Women's College of Liberal Arts, Kodo, Kyotanabe, Kyoto 610-0395, Japan \\ ${ }^{2}$ Department of Biochemistry and Molecular Biology, University of Louisville School of Medicine, Louisville, KY 40292, USA
}

Received December 5, 2008; Accepted December 27, 2008

\begin{abstract}
Polycyclic aromatic hydrocarbons (PAHs) and dioxins are ubiquitous environmental pollutants and activate the aryl hydrocarbon receptor (AhR), a ligand-activated transcription factor. It has been reported that testosterone represses 2,3,7,8-tetrachlorodibenzo- $p$-dioxininduced transcription of the cytochrome P450 (CYP) $1 \mathrm{~A} 1$ gene in LNCaP cells. In this study, we investigated the mechanism for the repression of 3-methylcholanthrene (3MC)-induced transcription of AhR-regulated genes, CYP1A1, CYP1A2, CYP1B1, and AhR repressor (AhRR), by $5 \alpha-$ dihydroteststerone (DHT) in $\mathrm{LNCaP}$ and T47D cells, which are androgen receptor (AR)- and AhR-positive. Real-time PCR analysis showed that DHT repressed 3MC-induced mRNA expression of the CYP1 family and AhRR genes. DHT repressed 3MC-induced luciferase activity in an AhR response element-driven luciferase reporter assay in LNCaP and T47D cells. The inhibitory effect of DHT was abolished by knockdown of AR protein with siRNA. The protein levels of AhR and AhR nuclear translocator (Arnt), the AhR-dimerizing partner, were not affected by DHT. Co-immunoprecipitation assay showed that DHT significantly facilitated the complex formation between AR and AhR in 3MC-treated cells. These results suggest that complex formation between activated AR and AhR plays an important role in the suppression of 3MC-induced transcription of CYP1 family genes by DHT.
\end{abstract}

Keywords: androgen receptor, aryl hydrocarbon receptor, cross-talk, complex formation, transcriptional activation

\section{Introduction}

Aryl hydrocarbon receptor (AhR) is a ligand-activated transcription factor that binds to various environmental pollutants containing polycyclic aromatic hydrocarbons (PAHs) and halogenated aromatic hydrocarbons such as dioxins (1). These compounds are found ubiquitously in the environment and are potently hazardous to human and animal health. Most of the toxic effects like endocrine-disrupting action and carcinogenesis are mediated by AhR $(2-7)$. Furthermore, AhR regulates normal

\footnotetext{
"Present address: Innovation of New Biomedical Engineering Center, Tohoku University, Seiryo-machi, Aoba-ku, Sendai, Miyagi 9808574, Japan

*Corresponding author. rkizu@dwc.doshisha.ac.jp Published online in J-STAGE on March 7, 2009 (in advance) doi: 10.1254 /jphs.08328FP
}

development of tissues, for example, reproductive tissues and liver, and diverse biological processes, including lipid synthesis, adipocyte differentiation, cell cycle progression, and immune system function $(5,8-11)$.

AhR is a member of the basic helix-loop-helix / PerArnt-Sim (bHLH/PAS) family of transcription factors (12). Other members of this family include Period (Per), AhR nuclear translocator (Arnt), Single-minded gene product $(\mathrm{Sim})$, Clock, hypoxia-inducible factor $1 \alpha$ $(\mathrm{HIF} 1 \alpha)$, and brain and muscle Arnt-like protein (BMAL). Unliganded AhR exists in a complex with heat shock protein 90 (HSP90), the HSP90 co-chaperone $\mathrm{p} 23$, and a hepatitis B virus $\mathrm{X}$-associated protein 2 (XAP2) in the cytoplasm $(13-15)$. Upon ligand binding, activated AhR is translocated from the cytoplasm into the nucleus and dimerizes with Arnt. The AhR/Arnt heterodimer binds to a specific DNA element, 
termed the xenobiotic response element (XRE), in the transcriptional regulatory region to regulate the transcription of AhR target genes including cytochrome P450 (CYP) 1A1, CYP1A2, CYP1B1, and AhR repressor genes $(16-18)$. These oxidative enzymes, CYP1A1, CYP1A2, and CYP1B1, metabolize PAHs to ultimate carcinogenic species.

Androgens regulate various functions during normal development and in adulthood. Especially, androgen is necessary for the development and maintenance of male reproductive organs including prostate, seminal vesicle, epididymis, and testis. Most of androgen's actions are mediated by the androgen receptor (AR). AR is a ligandactivated transcription factor and belongs to the steroid /thyroid hormone nuclear receptor superfamily (19). Unliganded AR predominantly exists in the cytoplasm. Upon ligand binding, activated AR is translocated into the nucleus where it recognizes and binds to a specific DNA element, termed the androgen response element (ARE), to regulate the transcription of AR target genes.

Dioxins and PAHs, acting as AhR ligands, are well-known disruptors of endocrine functions. There are numerous reports that 2,3,7,8-tetrachlorodibenzo- $p$ dioxin (TCDD), benzo[a]pyrene (BaP), and 3methylcholanthrene (3MC) repress AR-responsive biological processes. In utero and lactational exposures of male rats to TCDD decreased the weight of prostate, seminal vesicle, and epididymus $(8,20,21)$. In utero and lactational exposure of male rats to TCDD inhibits prostatic epithelial differentiation, formation of the epithelial bud to develop into secretory glands, and androgen-responsive mRNA expression in the prostate $(22,23)$. In human prostate cancer cells, TCDD, BaP, and $3 \mathrm{MC}$ repress androgen-induced gene transcription and cell proliferation $(24-29)$. Importantly, TCDD exerts inhibitory effects on prostate growth and development without inhibiting testicular androgen production $(21,23)$. Furthermore, we have reported that PAHs do not bind to AR (26). Cross-talk between AR- and AhRmediated signal transduction pathways plays an important role in the inhibitory effects of TCDD. Recent studies have shown several ways of cross-talk between AR- and AhR-mediated signal transduction pathways: 1) inhibition of androgen-induced transcriptional activation by AhR agonists, 2) transcriptional activation of androgen-regulated genes by $\mathrm{AhR}$ agonists in the absence of androgens, and 3) inhibition of AhR agonistinduced transcriptional activity by androgens.

First, an AhR agonist inhibited androgen-induced transcriptional activation by a mechanism involving complex formation between activated $\mathrm{AhR}$ and $\mathrm{AR}$ in which AhR acts as an E3 ubiquitin ligase to degrade AR protein (29). Second, in LNCaP cells, PAH caused induction of ARE-driven luciferase activity in the absence of androgens. For the mechanisms of the stimulatory effect of $\mathrm{AhR}$ agonists on androgenregulated gene, it is proposed that unliganded $A R$ forms a complex with activated AhR and binds to ARE in the transcriptional regulatory region of AR-regulated genes (30). Third, TCDD-induced CYP1A1 mRNA expression and CYP1A1 enzymatic activity, which was measured as ethoxyresorufin $O$-deethylase (EROD) activity, were inhibited by testosterone in $\mathrm{LNCaP}$ cells $(24,25)$. Also, TCDD-induced AhR-responsive luciferase reporter activity was inhibited by DHT in COS monkey kidney cells (31). However, the mechanism for the inhibitory effect of androgens on PAH-induced transcription of AhR-regulated genes has not yet been confirmed. Because of the importance of the cross-talk between AR and AhR-mediated signal transduction pathways in the toxic effects of AhR agonists, elucidation of the mechanism by which androgens repress PAH-induced transcription may help clarify AhR and AR functions. In this study, we reported that DHT represses 3MC-induced transcription of CYP1A1, CYP1A2, CYP1B1, and AhRR genes in LNCaP and T47D cells, and our results suggest that complex formation between AR and AhR is important for repression of $3 \mathrm{MC}$-induced gene transcription by DHT.

\section{Materials and Methods}

\section{Materials}

$5 \alpha$-Dihydrotestosterone (DHT) of biochemical study grade, 3MC ( $>99 \%$ pure), and dimethyl sulfoxide (DMSO) of ultra pure grade were purchased from Wako Pure Chemicals (Osaka). All other chemicals were of reagent grade or better and were obtained from commercial sources.

\section{Plasmids}

pGL3-XRE-SV40, an XRE-driven firefly luciferaseexpressing plasmid, was constructed by inserting three tandem repeats of the consensus XRE-containing sequence (5'-TCTTCTCACGCAACTCCGA-3') into the upstream region of the firefly luciferase gene in the pGL3-promoter vector (Promega, Madison, WI, USA). The underlined nucleotides are the consensus XRE. The sequence of pGL3-XRE-SV40 was confirmed by restriction enzymes digestion and by DNA sequencing (ABI PRISMR 3130/3130xl; Applied Biosystems, Foster City, CA, USA). Renilla luciferase expression pRLSV40 plasmid was purchased from Promega.

\section{Cell culture and treatment}

Human prostate cancer cell line LNCaP-FGC and 
human breast cancer cell line T47D were purchased from American Type Culture Collection (Manassas, VA, USA). LNCaP and T47D cells were grown in Dulbecco's modified Eagle's medium (DMEM; Sigma, St. Louis, MO, USA), supplemented with $10 \%$ fetal bovine serum (FBS; Biowest, Nuaillé, France), 100 units $/ \mathrm{ml}$ penicillin, and $100 \mu \mathrm{g} / \mathrm{ml}$ streptomycin) and were passaged with trypsinization every four days. Cell monolayers were maintained in an atmosphere of $5 \%$ $\mathrm{CO}_{2}$ and $95 \%$ air under a saturated humidity at $37^{\circ} \mathrm{C}$. In assays, the cells were plated in $10-\mathrm{cm}$ diameter dishes at a cell density of $1.8 \times 10^{6}$ cells/dish and cultured for $48 \mathrm{~h}$ in the growth medium. The cells were washed with phosphate-buffered saline (PBS) and cultured for $24 \mathrm{~h}$ in an assay medium [phenol red-free DMEM (Sigma) containing 5\% charcoal/dextran-treated FBS (Hyclone, Logan, UT, USA), 100 units $/ \mathrm{ml}$ penicillin, and $100 \mu \mathrm{g}$ $/ \mathrm{ml}$ streptomycin]. The cells were then treated with $0.1 \%$ DMSO, $1 \mu \mathrm{M} 3 \mathrm{MC}$ alone (3MC treatment), or in a combination with $10 \mathrm{nM}$ DHT (3MC/DHT treatment). Stock solutions of $3 \mathrm{MC}$ and DHT were prepared using DMSO and the final DMSO concentration in medium did not exceed $0.1 \%(\mathrm{v} / \mathrm{v})$.

\section{Reverse transcription and real-time PCR}

After the treatment, the cells were washed twice with PBS. Total RNA was extracted from the cells by using the RNeasy mini kit (Qiagen, Chatsworth, CA, USA). Reverse transcription was performed by using the ExScript RT reagent kit (Takara, Shiga) according to the manufacturer's instructions. Quantitative real-time PCR was carried out using SYBR premix ExTaq (Takara) on a Smart Cycler II System (Cepheid, Sunnyvale, CA, USA). Primer sequences are listed in Table 1. PCR conditions for repeated cycles were as follows: for CYP1A1 and CYP1A2, $95^{\circ} \mathrm{C}$ for $15 \mathrm{~s}$ and $60^{\circ} \mathrm{C}$ for $1 \mathrm{~min}$; for CYP1B1, $95^{\circ} \mathrm{C}$ for $15 \mathrm{~s}$ and $65^{\circ} \mathrm{C}$ for $30 \mathrm{~s}$; for AhRR, $95^{\circ} \mathrm{C}$ for $15 \mathrm{~s}, 56^{\circ} \mathrm{C}$ for $5 \mathrm{~s}$, and $72^{\circ} \mathrm{C}$ for $8 \mathrm{~s}$; for

Table 1. Primers used in this study

\begin{tabular}{lll}
\hline Gene & & Primer sequence $\left(5^{\prime}-3^{\prime}\right)$ \\
\hline CYP1A1 & Forward & GTCATCTGTGCCATTTGCTTTG \\
& Reverse & CAACCACCTCCCCGAAATTATT \\
CYP1A2 & Forward & TGTTCAAGCACAGCAAGAAGG \\
& Reverse & TGCTCCAAAGACGTCATTGAC \\
CYP1B1 & Forward & AACGTCATGAGTGCCGTGTGT \\
& Reverse & GGCCGGTACGTTCTCCAAATC \\
AhRR & Forward & ACCGCGGATGCAAAAGTAAAAG \\
& Reverse & GCTCCTTCCTGCTGAGTAATTGG \\
RPLP0 & Forward & GGCGACCTGGAAGTCCAACT \\
& Reverse & CCATCAGCACCACAGCCTTC \\
\hline
\end{tabular}

RPLP0, $95^{\circ} \mathrm{C}$ for $5 \mathrm{~s}$ and $66^{\circ} \mathrm{C}$ for $20 \mathrm{~s}$. The RPLP0 product was used as a control to assure that equal amounts of RNA were used.

\section{Dual luciferase reporter assay}

LNCaP cells ware plated at a cell density of $1.2 \times 10^{5}$ cells/well in 12-well plates and cultured for $48 \mathrm{~h}$ in growth medium. The cells were then washed with PBS and transiently transfected with pGL3-XRE-SV40 $(0.8 \mu \mathrm{g} /$ well $)$ and pRL-SV40 $(0.04 \mu \mathrm{g} /$ well $)$ using the lipofection reagent Lipofectamine (Invitrogen, Carlsbad, $\mathrm{CA}$, USA) for $5 \mathrm{~h}$ at $37^{\circ} \mathrm{C}$, according to the manufacturer's instructions. The cells were washed once with PBS and cultured in the fresh assay medium. At 48-h post-transfection, cells were treated $12 \mathrm{~h}$ with DHT and $3 \mathrm{MC}$ at the given concentrations. Luciferase activity was determined with the PicaGene Dual Sea Pansy Luminescence Kit (Toyo Ink, Tokyo). Firefly luciferase activity was normalized to the Renilla luciferase activity.

\section{Whole cell and nuclear extracts preparation}

After the treatment with $3 \mathrm{MC}$ or $3 \mathrm{MC} / \mathrm{DHT}$, whole cell and nuclear extracts were prepared using CelLytic $M$ and CelLytic NuCLEAR Extraction Kits (Sigma), respectively, according to the manufacturer's instructions. Protein concentrations were determined using Protein Assay CBB Solution $(5 \times)$ (Nacalai Tesque, Kyoto).

\section{siRNA treatment}

AR siRNA (5'-gaccuaccgaggagcuuucdTdT-3') was directed against nucleotides 51-71 downstream of the start codon of the human AR gene (32). A negative control (non-silencing) siRNA (5'-uucuccgaacgugucacgudTdT-3'), purchased from Qiagen, was used as a negative control. Cells were plated in $10-\mathrm{cm}$ diameter dishes at a cell density of $1.2 \times 10^{6}$ cells $/$ dish and cultured for $48 \mathrm{~h}$ in growth medium. The cells were then washed with PBS and transfected with siRNA for nonsilencing or AR at an siRNA concentration of $100 \mathrm{nM}$ for $24 \mathrm{~h}$ using RNAiFect Transfection Reagent (Qiagen) in Opti-MEM serum-free medium (Invitrogen), according to the manufacturer's instructions. Cells were then subjected to the quantitative real-time PCR assay.

\section{Western blotting}

Whole cell and nuclear extracts containing equal amounts of protein were separated by SDS-PAGE ( $5 \%$ $20 \%$ acrylamide gel) and transferred to polyvinylidene difluoride membranes (Millipore, Billerica, MA, USA). The membrane was blocked in Tris-buffered saline containing $0.1 \%$ Tween- 20 and $5 \%$ non-fat milk and then probed with rabbit anti-human AhR polyclonal 
antibody (sc-5579; Santa Cruz Biotechnology, Santa Cruz, CA, USA), rabbit anti-human AR polyclonal antibody (06-680, Millipore), rabbit anti-human Arnt polyclonal antibody (sc-5580, Santa Cruz Biotechnology), or rabbit anti-human RPLP0 polyclonal antibody (HPA003512, Sigma), followed by peroxidaseconjugated secondary anti-mouse or rabbit immunoglobulin (IgG) antibodies (GE Healthcare UK, Ltd., Buckinghamshire, England). Membranes were then visualized with chemiluminescent detection reagents: ECL Plus (GE Healthcare) for AhR and Chemi-Lumi One (Nacalai Tesque) for AR, Arnt, and RPLP0, by using LumiVision PRO 400EX (Aisin Seiki, Aichi). LumiVision Analyzer 400 (Aisin Seiki) was used to digitalize and analyze the relative amounts of protein, based on pixel density, in the immunoblot bands.

\section{Co-immunoprecipitation}

Nuclear extracts were initially precleared by incubation with Protein G Sepharose 4 Fast Flow, protein Gcoupled Sepharose beads (GE Healthcare). The clarified nuclear extracts were then incubated with goat antihuman AhR polyclonal antibody (sc-8088, Santa Cruz Biotechnology) in immunoprecipitation buffer [20 mM Hepes-NaOH (pH 7.5), $150 \mathrm{mM} \mathrm{NaCl}, 5 \mathrm{mM}$ EGTA, $1 \mathrm{mM}$ EDTA, $60 \mathrm{mM} \beta$-glycerophosphate, $20 \mathrm{mM} \mathrm{NaF}$, $0.5 \%$ Tween $20,0.5 \%$ IGEPAL CA-630 (Sigma), $0.5 \%$ sodium deoxycholate, $1 \mathrm{mM}$ DTT, protease inhibitor cocktail (Sigma)] under gentle agitation overnight at $4^{\circ} \mathrm{C}$. Protein G Sepharose 4 Fast Flow beads were then added to the immunocomplexes and incubated for $2 \mathrm{~h}$ under gentle agitation at $4^{\circ} \mathrm{C}$. AR and $\mathrm{AhR}$ proteins in the precipitates were analyzed by the western blotting technique described above.

\section{Statistical analyses}

Statistical analyses were performed by the unpaired Student's $t$-test, whereby a value of $P<0.05$ was considered to be significant.

\section{Results}

Repression of 3MC-induced transcription by DHT in $A R$ - and AhR-positive cells

It has reported that the inhibitory effect of testosterone was evaluated on the CYP1A1 gene in $\mathrm{LNCaP}$ cells (24). It is uncertain whether testosterone represses transcription of AhR-regulated genes other than CYP1A1. First of all, we examined the effect of DHT on PAH-induced transcription of AhR-regulated genes, CYP1A2, CYP1B1, and AhRR in addition to CYP1A1, in LNCaP and T47D cells by the quantitative real-time PCR technique. The results for $\mathrm{LNCaP}$ cells are shown
(A) LNCaP
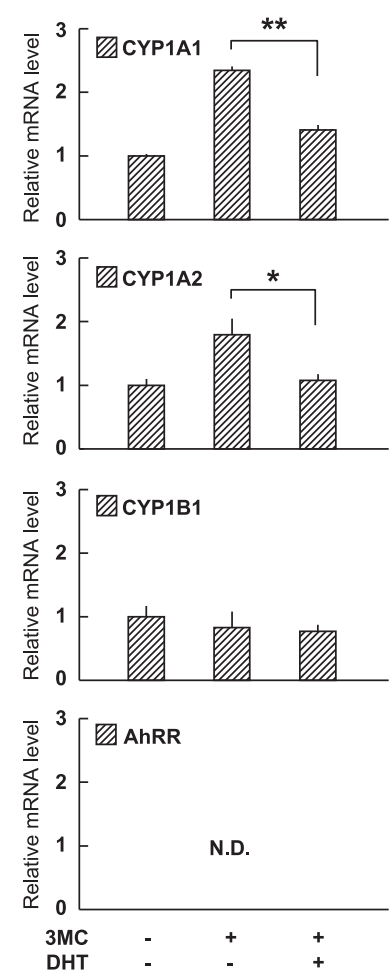

(B) T47D
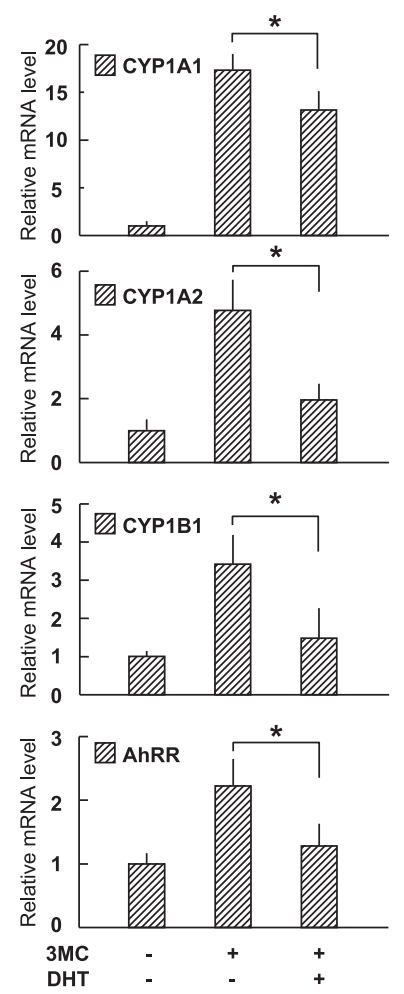

Fig. 1. Repression of 3MC-induced mRNA expression of CYP1A1, CYP1A2, CYP1B1, and AhRR genes by DHT in LNCaP (A) and T47D (B) cells. Cells were treated with $0.1 \%$ DMSO, $1 \mu \mathrm{M} 3 \mathrm{MC}$, or $1 \mu \mathrm{M} 3 \mathrm{MC}$ in combination with $10 \mathrm{nM}$ DHT for $12 \mathrm{~h}$. CYP1A1, CYP1A2, CYP1B1, and AhRR mRNA levels were measured by realtime PCR. The RPLP0 product was analyzed as a control to assure that equal amounts of RNA were used. Each column and vertical bar represents the mean \pm S.D. of three separate experiments. * and **: Significantly different at $P<0.05$ and $P<0.01$, respectively. N.D. $=$ not detected

in Fig. 1A. 3MC increased the mRNA levels of CYP1A1 and CYP1A2, and their inductions were significantly repressed by DHT by approximately $70 \%$ and $90 \%$, respectively. CYP1B1 mRNA level was not induced by $3 \mathrm{MC}$ as noted in previous reports (25). AhRR mRNA was not detected in LNCaP cells. In T47D cells, 3MC increased the mRNA levels of all four genes, and the inductions of CYP1A1, CYP1A2, CYP1B1, and AhRR mRNA levels were repressed by DHT by approximately $25 \%, 75 \%, 80 \%$, and $75 \%$, respectively.

We performed dual luciferase reporter assays using pGL3-XRE-SV40, an XRE-driven luciferase expression vector. 3MC-induced XRE-driven luciferase activity in LNCaP and T47D cells (Fig. 2). DHT repressed this induction of luciferase activity in $\mathrm{LNCaP}$ and $\mathrm{T} 47 \mathrm{D}$ cells by approximately $90 \%$ and $50 \%$, respectively.

Involvement of $A R$ in the inhibitory effect of DHT

To determine whether AR is required for the inhibitory 
A

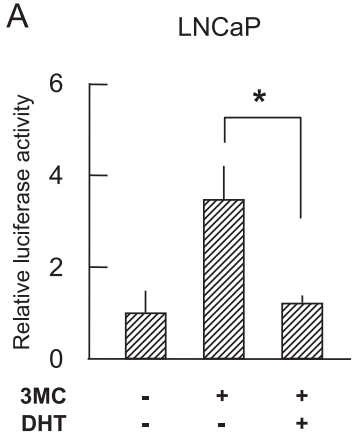

B

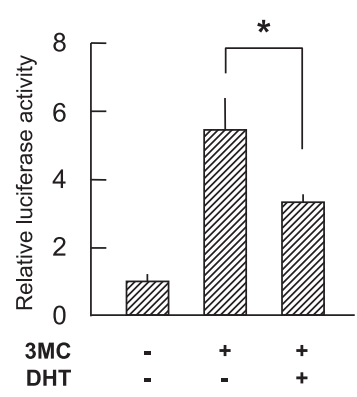

Fig. 2. Repression of 3MC-induced XRE-driven luciferase activity by $\mathrm{DHT}$ in $\mathrm{LNCaP}$ (A) and T47D (B) cells. LNCaP and T47D cells were transfected with pGL3-XRE-SV40 XRE-driven firefly luciferase expression vector and pRL-SV40 renilla luciferase expression vector. At $48 \mathrm{~h}$ post-transfection, cells were treated with $0.1 \%$ DMSO, $1 \mu \mathrm{M} 3 \mathrm{MC}$ alone, or $1 \mu \mathrm{M} 3 \mathrm{MC}$ in combination with $10 \mathrm{nM}$ DHT for $12 \mathrm{~h}$. The firefly luciferase activity was normalized by the Renilla luciferase activity. Each column and vertical bar represents the mean \pm S.D. of four separate experiments. *: Significantly different at $P<0.05$.

effect of DHT, AR protein was knocked down using siRNA in LNCaP cells. The specificity of AR knockdown was confirmed by western blotting. AR protein levels decreased significantly with time and reached a minimum 4-day post-transfection in AR siRNA-transfected cells, whereas non-silencing siRNA-transfected cells showed no observable change in AR protein levels (Fig. 3A). AR-knockdown cells were subjected to real-time PCR assay using CYP1A1-specific primers. As shown in Fig. 3B, 3MC increased the mRNA level of CYP1A1 in LNCaP cells treated with AR siRNA or non-silencing siRNA. The induction of CYP1A1 mRNA expression was significantly reduced by DHT in non-silencing siRNA-treated LNCaP cells, whereas DHT showed almost no effect on the CYP1A1 mRNA level in the AR siRNA-treated cells. These results indicate that AR protein is necessary for the inhibitory effect of DHT on $3 \mathrm{MC}$-induced transcription of CYP1 family genes.

\section{Effect of DHT on cellular protein levels of AhR and Arnt}

To determine if DHT affects the cellular AhR and Arnt protein levels, western blotting of whole cell extracts from 3MC- or 3MC/DHT-treated LNCaP cells was performed. As shown in Fig. 4, while AhR protein levels in whole cell extracts were significantly reduced by $3 \mathrm{MC}$, the AhR protein levels in whole cell extracts were similar in 3MC- and 3MC/DHT-treated cells. Activation of AhR by $3 \mathrm{MC}$ brings about reduction in AhR protein level through activation of the ubiquitinproteasome system $(29,33)$. Reduction in cellular AhR protein level by $3 \mathrm{MC}$ was observed and this result is consistent with reported knowledge. Arnt, the dimeriza-

A

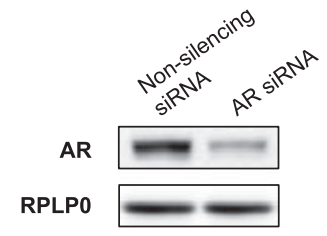

B
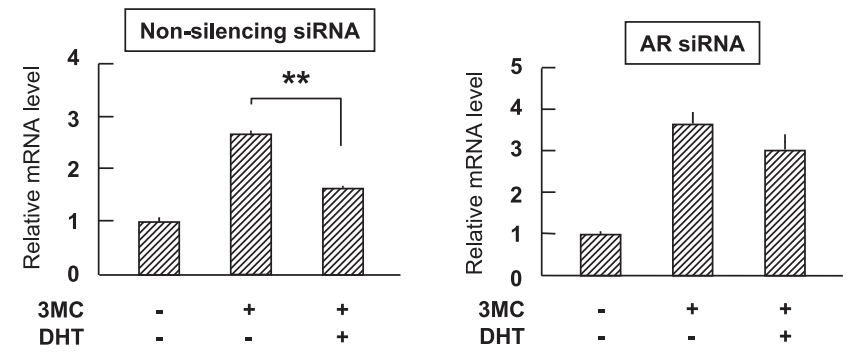

Fig. 3. Involvement of AR in the inhibitory effect of DHT. LNCaP cells were transfected with the non-silencing siRNA or AR siRNA and then treated with $0.1 \%$ DMSO, $1 \mu \mathrm{M} 3 \mathrm{MC}$ alone, or $1 \mu \mathrm{M} 3 \mathrm{MC}$ in combination with $10 \mathrm{nM}$ DHT for $12 \mathrm{~h}$, followed by Western blotting analysis (A) or real-time PCR assay (B). In the Western blotting analysis, AR and RPLP0 protein levels in whole cell extracts were measured. In the real-time PCR assay, CYP1A1 mRNA expression levels were measured. The RPLP0 product was analyzed as a control to assure that equal amounts of RNA were used. Each column and vertical bar represents the mean \pm S.D. of three separate experiments. **: Significantly different at $P<0.01$.

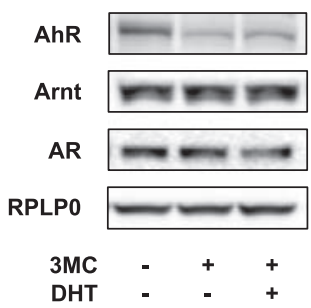

Fig. 4. Effect of DHT on protein levels of AhR and Arnt. LNCaP cells were incubated with $0.1 \%$ DMSO, $1 \mu \mathrm{M} 3 \mathrm{MC}$ alone, or $1 \mu \mathrm{M}$ $3 \mathrm{MC}$ in combination with $10 \mathrm{nM}$ DHT for $60 \mathrm{~min}$. Whole cell extracts were then prepared and subjected to western blot analyses of AhR and AR. The RPLP0 protein level was analyzed as a control to assure that equal amounts of whole proteins were used.

tion partner of $\mathrm{AhR}$, showed no change at the protein level in whole cell extracts with $3 \mathrm{MC}$ - or $3 \mathrm{MC} / \mathrm{DHT}$ tratment. These results demonstrate that DHT does not cause a decrease in the cellular protein levels of either AhR or Arnt, which leads to the inhibitory effect of DHT.

\section{Complex formation of AR with AhR}

Next, we investigated whether DHT affects the translocation of AhR from the cytoplasm to the nucleus. Figure 5A shows the time-course of AhR levels in nuclear extracts of $\mathrm{LNCaP}$ cells following $3 \mathrm{MC}$ - or 
A

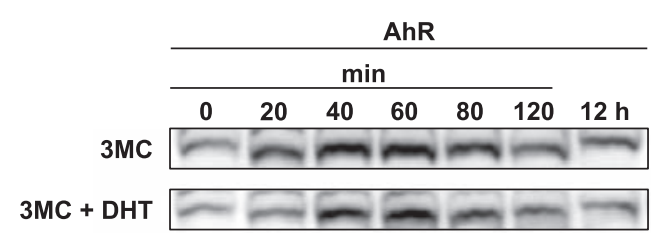

B

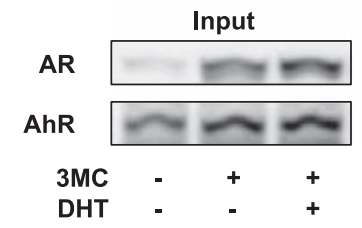

C

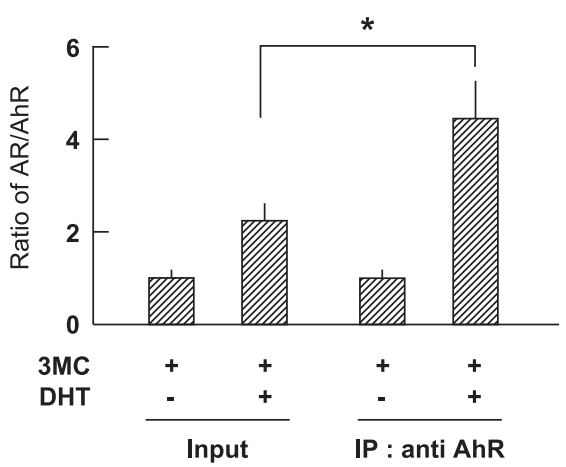

Fig. 5. Complex formation of $A R$ with $A h R$ in nuclear extracts. A: $\mathrm{LNCaP}$ cells were treated with $1 \mu \mathrm{M} 3 \mathrm{MC}$ alone or $1 \mu \mathrm{M} 3 \mathrm{MC}$ in combination with $10 \mathrm{nM}$ DHT for the indicated times. Nuclear extracts were prepared and analyzed for AhR by the western blot technique. B: $\mathrm{LNCaP}$ cells were treated with $0.1 \%$ DMSO, $1 \mu \mathrm{M}$ $3 \mathrm{MC}$ alone, or $1 \mu \mathrm{M} 3 \mathrm{MC}$ in combination with $10 \mathrm{nM}$ DHT for $60 \mathrm{~min}$. Nuclear extracts were prepared and input levels of AR and AhR were examined by Western blot analysis. Nuclear extracts were subjected to the co-immunoprecipitation assay coupled with anti-AhR antibodies. AR and AhR in the immunoprecipitates were analyzed by the Western blot technique. C: The AR protein level was normalized to the AhR protein level (AR/AhR). Ratios of AR/AhR protein levels of input control and immunoprecipitates of $A h R$ are shown. Each column and vertical bar represents the mean \pm S.D. of three separate experiments. *: Significantly different at $P<0.05$.

3MC/DHT-treatment. AhR levels in the nuclear extracts peaked at 40 to $60 \mathrm{~min}$ after treatment and then declined slowly. A significant difference in the time-course of nuclear AhR level was not observed between 3MC- and 3MC/DHT treatments.

To determine whether AhR forms a complex with $\mathrm{AR}$ in the nucleus of $\mathrm{LNCaP}$ cells treated with $3 \mathrm{MC}$ or $3 \mathrm{MC} / \mathrm{DHT}$, nuclear extracts were immunoprecipitated with an anti-AhR antibody and blotted for AR and AhR. First, we measured the protein levels of AhR and AR in nuclear extracts from 3MC- or 3MC/DHT-treated cells (input control). As shown in Fig. 5B (left panel), 3MC- treatment increased nuclear $\mathrm{AhR}$ and $\mathrm{AR}$ protein levels and 3MC/DHT-treatment further increased nuclear AR-protein levels. The nuclear AhR-protein levels were similar in 3MC- and 3MC/DHT-treated cells. AR was co-immunoprecipitated with $\mathrm{AhR}$ in nuclear extracts from cells treated with $3 \mathrm{MC}$ and $3 \mathrm{MC} / \mathrm{DHT}$ (Fig. 5B: right panel). While the ratio of $\mathrm{AR} / \mathrm{AhR}$ was increased with both input control and immunoprecipitates of AhR by co-treatment with DHT, the magnitude of the increase was significantly greater with immunoprecipitates (Fig. 5C). AR was not detected in the immunoprecipitates of the cells treated with $0.1 \%$ DMSO. Taken together, these results suggest that DHT significantly facilitated the formation of a complex between $\mathrm{AR}$ and $\mathrm{AhR}$ in the nucleus of 3MC-treated cells.

\section{Discussion}

Several types of cross-talk between AR- and AhRmediated signal transduction pathways have been reported. The elucidation of the mechanisms for ARAhR cross-talk may contribute to a better understanding of the function of AR and AhR in normal development and the toxicities of AhR agonists.

One example of AR-AhR cross-talk is the report that testosterone repressed TCDD-induced transcription of AhR-regulated CYP1A1 gene and CYP1A1 enzymatic activity in LNCaP cells $(24,25)$. However, the mechanism by which testosterone represses TCDD-induced transcription remains unclear. The present study was undertaken to get further insight into the mechanism of the inhibitory effect of testosterone. In a previous study (24), the inhibitory effect of testosterone was evaluated only on the CYP1A1 gene in LNCaP cells. AR expressed in LNCaP cells has a mutation (Thr877 to Ala in ligand-binding domain). In the present study, we used DHT as an androgen and assayed the inhibitory effects of DHT against CYP1A2, CYP1B1, and AhRR genes, typical activated AhR-regulated genes, in addition to CYP1A1. T47D breast cancer cells were also used because they express wild type AR. DHT repressed $3 \mathrm{MC}$-induced transcription with all four genes in both LNCaP and T47D cells (Fig. 1). These results suggest that repression of AhR-regulated gene transcription by DHT is not due to mutant AR and a general phenomenon in AhR- and AR-positive cells. While AhRR functions to repress the transcriptional activity of AhR (18), AhRR mRNA levels were actually reduced in 3MC/DHTtreated cells (Fig. 1), indicating that AhRR is not involved in the inhibitory effect of DHT.

It is possible that activated AR or other transcription factors bind to cis-elements, except for XRE, present in the transcriptional regulatory regions of these AhR- 
regulated genes to suppress the transcriptional activation. The inhibitory effect of DHT was observed in the XRE-driven luciferase reporter assay in this study (Fig. 2). Furthermore, similar effects were observed in a luciferase reporter assay in COS cells transfected with vectors expressing human AR and AhR (31). These results indicate that the presence of the XRE is sufficient for DHT to inhibit AhR-activated transcription. The inhibitory effects of DHT on 3MC-induced CYP1 family mRNA levels and XRE-driven luciferase activity are more pronounced in $\mathrm{LNCaP}$ cells than in $\mathrm{T} 47 \mathrm{D}$ cells. Therefore, we used LNCaP cells in the subsequent experiments.

We verified that $A R$ is involved in the repression of 3MC-induced transcription by DHT using the AR knockdown technique with AR siRNA (Fig. 3).

While the reduction in AhR and/or Arnt protein levels would lead to decreased induction of AhR-regulated genes, DHT did not alter the cellular AhR and Arnt protein levels in 3MC-treatment (Fig. 4).

It is needless to say that activated AhR must be translocated from the cytoplasm to the nucleus and then bind to DNA in order to activate the transcription. So, we examined the effect of DHT on translocation of AhR to the nucleus. As shown in Fig. 5A, DHT did not affect the translocation of AhR to the nucleus. Then, we examined whether complex formation between AR and AhR was altered by DHT in the nucleus. DHT significantly facilitated the formation of a complex between $\mathrm{AR}$ and AhR in the nucleus of 3MC-treated cells (Fig. 5: $\mathrm{B}$ and $\mathrm{C}$ ), and these results suggest that complex formation between $\mathrm{AR}$ and $\mathrm{AhR}$ plays an important role in the repression of 3MC-induced transcription of CYP1 family genes by DHT. We have obtained some results showing that activated AhR binds to unliganded AR and causes translocation of $\mathrm{AR}$ to the nucleus from the cytoplasm (manuscript in preparation). Activated AhR had a similar effect in LNCaP cells (30). So, AR protein is detected in the nuclear extracts and in the immunoprecipitates of AhR from the 3MC-treated cells (Fig. 5B).

We propose two hypotheses to account for the molecular mechanism of the suppressive effects of DHT that we have reported here: 1) AhR in a complex with AR has decreased binding affinity for the XRE. This suggestion is based on the observation that AR and c-Jun form a complex that has reduced DNA binding ability and results in mutual repression of AR- and AP1regulated gene transcription (34). Arnt is supposed to play an important role in binding of AhR/Arnt heterodimer to DNA since the CAC half-site of the core sequence of XRE (CACGC) was expected to be recognized by Arnt $(35,36)$. If AR inhibits the dimerization of AhR with Arnt by complex formation between
$\mathrm{AR}$ and $\mathrm{AhR}$, the binding of $\mathrm{AhR}$ to the $\mathrm{XRE}$ is repressed. 2) After complex formation between AR and AhR and XRE binding, we hypothesize that recruitment of coactivators and the formation of the transcriptional machinery is inhibited due to steric hindrance caused by AR bound to AhR.

In conclusion, DHT represses 3MC-induced transcription of AhR-regulated genes, CYP1A1, CYP1A2, CYP1B1, and AhRR in LNCaP and T47D cells. While complex formation between AR and AhR was observed with both activated and unliganded $\mathrm{AR}$, the complex was enriched in the nuclear extracts of 3MC/DHTtreated cells compared to 3MC-treated cells. These results suggest that DHT suppresses 3MC-induced transcription of AhR-regulated genes by facilitating complex formation between $\mathrm{AR}$ and $\mathrm{AhR}$ that results in reduced transcriptional activity.

\section{Acknowledgments}

This work was supported by a Grant-in-Aid for Young Scientists (B) (No. 20790120) to N. Sanada and a Grant-in-Aid Scientific Research (C) (No. 19590128) to R. Kizu from the Ministry of Education, Culture, Sports, Science, and Technology of Japan and Project Research Grants to R. Kizu and R. Shimazawa from Doshisha Women's College of Liberal Arts.

\section{References}

1 Hankinson O. The aryl hydrocarbon receptor complex. Annu Rev Pharmacol Toxicol. 1995;35:307-340.

2 Shimizu Y, Nakatsuru Y, Ichinose M, Takahashi Y, Kume H, Mimura $\mathrm{J}$, et al. Benzo[a]pyrene carcinogenicity is lost in mice lacking the aryl hydrocarbon receptor. Proc Natl Acad Sci U S A. 2000;97:779-782.

3 Safe SH. Modulation of gene expression and endocrine response pathways by 2,3,4,8-tetrachlorodibenzo- $p$-dioxin and related compounds. Pharmacol Ther. 1995;67:247-281.

4 Santodonato J. Review of the estrogenic and antiestrogenic activity of polycyclic aromatic hydrocarbons: Relationship to carcinogenicity. Chemosphere. 1997;34:835-848.

5 Fernandez-Salguero PM, Hilbert DM, Rudikoff S, Ward JM, Gonzalez FJ. Aryl-hydrocarbon receptor-deficient mice are resistant to 2,3,7,8-tetrachlorodibenza- $p$-dioxin-induced toxicity. Toxicol Appl Pharmacol. 1996;140:173-179.

6 Mimura J, Fujii-Kuriyama Y. Functional role of AhR in the expression of toxic effects by TCDD. Biochim Biophys Acta. 2003;1619:263-268.

7 Peters JM, Narotsky MG, Elizondo G, Fernandez-Salguero PM, Gonzalez FJ, Abbott BD. Amelioration of TCDD-induced teratogenesis in aryl hydrocarbon receptor (AhR)-null mice. Toxicol Sci. 1999;47:86-92.

8 Lin TM, Ko K, Moore RW, Simanainen U, Oberley TD, Peterson RE. Effects of aryl hydrocarbon receptor null mutation and in utero and lactational 2,3,7,8-tetrachlorodibenzo- $p$-dioxin exposure on prostate and seminal vesicle development in C57BL/6 mice. Toxicol Sci. 2002;68:479-487. 
9 Alexander DL, Ganem LG, Fernandez-Salguero P, Gonzalez F, Jefcoate CR. Aryl-hydrocarbon receptor is an inhibitory regulator of lipid synthesis and of commitment to adipogenesis. J Cell Sci. 1998;111:3311-3322.

10 Elizondo G, Fernandez-Salguero P, Sheikh MS, Kim GY, Fornace AJ, Lee KS, et al. Altered cell cycle control at the $\mathrm{G}_{2} / \mathrm{M}$ phases in aryl hydrocarbon receptor-null embryo fibroblast. Mol Pharmacol. 2000;57:1056-1063.

11 Fernandez-Salguero P, Pineau T, Hilbert DM, McPhail T, Lee SS, Kimura S, et al. Immune system impairment and hepatic fibrosis in mice lacking the dioxin-binding Ah receptor. Science. 1995;268:722-726.

12 Furness SG, Lees MJ, Whitelaw ML. The dioxin (aryl hydrocarbon) receptor as a model for adaptive responses of bHLH /PAS transcription factors. FEBS Lett. 2007;581:3616-3625.

13 Perdew GH. Chemical cross-linking of the cytosolic and nuclear forms of the Ah receptor in hepatoma cell line 1c1c7. Biochem Biophys Res Commun. 1992;182:55-62.

14 Chen HS, Perdew GH. Subunit composition of the heteromeric cytosolic aryl hydrocarbon receptor complex. J Biol Chem. 1994;269:27554-27558.

15 Meyer BK, Pray-Grant MG, Vanden Heuvel JP, Perdew GH. Hepatitis B virus X-associated protein 2 is a subunit of the unliganded aryl hydrocarbon receptor core complex and exhibits transcriptional enhancer activity. Mol Cell Biol. 1998;18:978988.

16 Dong L, Ma Q, Whitlock JP Jr. DNA binding by the heterodimeric $\mathrm{Ah}$ receptor. Relationship to dioxin-induced CYP1A1 transcription in vivo. J Biol Chem. 1996;271:79427948.

17 Fujii-Kuriyama Y, Mimura J. Molecular mechanisms of AhR function in the regulation of cytochrome P450 genes. Biochem Biophys Res Commun. 2005;338:311-317.

18 Mimura J, Ema M, Sogawa K, Fujii-Kuriyama Y. Identification of a novel mechanism of regulation of Ah (dioxin) receptor function. Genes Dev. 1999;13:20-25.

19 Mangelsdorf DJ, Thummel C, Beato M, Herrlich P, Schütz G, Umesono K, et al. Cell. The nuclear receptor superfamily: the second decade. 1995;83:835-839.

20 Mably TA, Moore RW, Peterson RE. In utero and lactational exposure of male rats to 2,3,7,8-tetrachlorodibenzo- $p$-dioxin. 1 . Effects on androgenic status. Toxicol Appl Pharmacol. 1992; 114:97-107.

21 Gray LE Jr, Kelce WR, Monosson E, Ostby JS, Birnbaum LS. Exposure to TCDD during development permanently alters reproductive function in male Long Evans rats and hamsters: reduced ejaculated and epididymal sperm numbers and sex accessory gland weights in offspring with normal androgenic status. Toxicol Appl Pharmacol. 1995;131:108-118.

22 Theobald HM, Roman BL, Lin TM, Ohtani S, Chen SW, Peterson RE. 2,3,7,8-tetrachlorodibenzo-p-dioxin inhibits luminal cell differentiation and androgen responsiveness of the ventral prostate without inhibiting prostatic 5alpha-dihydrotestosterone formation or testicular androgen production in rat offspring. Toxicol Sci. 2000;58:324-338.

23 Roman BL, Sommer RJ, Shinomiya K, Peterson RE. In utero and lactational exposure of the male rat to 2,3,7,8tetrachlorodibenzo-p-dioxin: impaired prostate growth and development without inhibited androgen production. Toxicol Appl Pharmacol. 1995;134:241-250.

24 Jana NR, Sarkar S, Ishizuka M, Yonemoto J, Tohyama C, Sone H. Cross-talk between 2,3,7,8-tetrachlorodibenzo- $p$-dioxin and testosterone signal transduction pathways in $\mathrm{LNCaP}$ prostate cancer cells. Biochem Biophys Res Commun. 1999;256:462468.

25 Jana NR, Sarkar S, Ishizuka M, Yonemoto J, Tohyama C, Sone H. Comparative effects of 2,3,7,8-tetrachlorodibenzo- $p$-dioxin on MCF-7, RL95-2, and LNCaP cells: Role of target steroid hormones in cellular responsiveness to CYP1A1 induction. Mol Cell Biol Res Commun. 2000;4:174-180.

26 Kizu R, Okamura K, Toriba A, Kakishima H, Mizokami A, Burnstein KL, et al. A role of aryl hydrocarbon receptor in the antiandrogenic effects of polycyclic aromatic hydrocarbons in LNCaP human prostate carcinoma cells. Arch Toxicol. 2003;77: 335-343.

27 Barnes-Ellerbe S, Knudsen KE, Puga A. 2,3,7,8-Tetrachlorodibenzo-p-dioxin blocks androgen-dependent cell proliferation of LNCaP cells through modulation of $\mathrm{pRB}$ phosphorylation. Mol Pharmacol. 2004;66:502-511.

28 Kizu R, Ishii K, Kobayashi J, Hashimoto T, Koh E, Namiki M, et al. Antiandrogenic effect of crude extract of C-heavy oil. Mat Sci Eng C. 2000;12:97-102.

29 Ohtake F, Baba A, Takada I, Okada M, Iwasaki K, Miki H, et al. Dioxin receptor is a ligand-dependent E3 ubiquitin ligase. Nature. 2007;446:562-566.

30 Ohtake F, Baba A, Fujii-Kuriyama Y, Kato S. Intrinsic AhR function underlies cross-talk of dioxins with sex hormone signalings. Biochem Biophys Res Commun. 2008;370:541-546.

31 Kollara A, Brown TJ. Functional interaction of nuclear receptor coactivator 4 with aryl hydrocarbon receptor. Biochem Biophys Res Commun. 2006;346:526-534.

32 Hååg P, Bektic J, Bartsch G, Klocker H, Eder IE. Androgen receptor down regulation by small interference RNA induces cell growth inhibition in androgen sensitive as well as in androgen independent prostate cancer cells. J Steroid Biochem Mol Biol. 2005;96:251-258.

33 Pollenz RS, Buggy C. Ligand-dependent and -independent degradation of the human aryl hydrocarbon receptor (hAHR) in cell culture models. Chem Biol Interact. 2006;164:49-59.

34 Sato N, Sadar MD, Bruchovsky N, Saatcioglu F, Rennie PS, Sato $\mathrm{S}$, et al. Androgenic induction of prostate-specific antigen gene is repressed by protein-protein interaction between the androgen receptor and AP-1/c-Jun in the human prostate cancer cell line LNCaP. J Biol Chem. 1997;272:17485-17494.

35 Swanson HI, Chan WK, Bradfield CA. DNA binding specificities and pairing rules of the Ah receptor, ARNT, and SIM proteins. J Biol Chem. 1995;270:26292-26302.

36 Bacsi SG, Reisz-Porszasz S, Hankinson O. Orientation of the heterodimeric aryl hydrocarbon (dioxin) receptor complex on its asymmetric DNA recognition sequence. Mol Pharmacol. 1995;47:432-438. 